\title{
New Data from an Open Neolithic Site in Eastern Indonesia
}

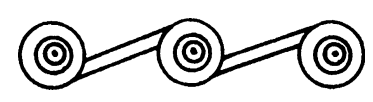

\author{
Peter Lape, Emily Peterson, Daud Tanudirjo, Chung-Ching Shiung, \\ Gyoung-Ah LeE, Judith Field, and Adelle Coster
}

\begin{abstract}
Here we report the results of excavation and analyses of an open site on Pulau Ay, a small (ca. $4 \mathrm{~km}^{2}$ ) limestone island located in the Banda Islands, central Maluku, Indonesia. This report provides results of excavations at PA1 and other Pulau Ay sites conducted in 2007 and 2009. These sites reveal patterns of changes in marine resource exploitation, pottery, and use of domestic animals, particularly between initial occupation of the site at approximately 3500 B.P., and later phases commencing approximately 3000 B.P. Archaeobotanical analyses reported here provide insight into early Neolithic plant use, including early use of Myristica fragans (nutmeg) in a food context. The PA1 site adds to a growing data set about early Neolithic lifeways in Island Southeast Asia and provides a new view of cultural adaptations happening in the region during this critical period. KEYwORDS: Neolithic, agriculture, archaeology, Island Southeast Asia, eastern Indonesia, Maluku.
\end{abstract}

\section{INTRODUCTION}

Here we report the results of excavation and analyses of AN open Site on Pulau Ay, a small $\left(\mathrm{ca} .4 \mathrm{~km}^{2}\right.$ ) limestone island located in the Banda Islands, central Maluku, Indonesia (Fig. 1). The PA1 site is a well-stratified open site, first excavated by Lape in 1997 (Lape 2000). This report provides results of excavations at PA1 and other Pulau Ay sites conducted in 2007 and 2009. These sites reveal patterns of changes in marine resource exploitation, pottery, and use of domestic animals, particularly between initial occupation of the site at approximately 3500 B.P. and later phases commencing approximately 3000 B.P. Relatively few sites in Indonesia contain pottery pre-dating 3000 B.P. and the vast majority of those sites are located in caves (O'Connor 2015; Spriggs 2003, 2007). Caves were seldom used for long term-occupation in central

Peter Lape is a Professor of Anthropology at the University of Washington, Seattle. Emily Peterson is a Research Associate at the Burke Museum, University of Washington, Seattle. Daud Tanudirjo is a Professor of Archaeology at Universitas Gadjah Mada, Yogyakarta, Indonesia. Chung-Ching Shiung is an Assistant Professor of Archaeology at the Institute of Archaeology at the National Cheng Kung University, Taiwan. Gyoung-Ah Lee is an Associate Professor of Anthropology at the University of Oregon, Eugene. Judith Field is an Honorary Senior Lecturer in the School of Biological, Earth and Environmental Sciences at the University of New South Wales, Australia. Adelle Coster is an Associate Professor of Applied Mathematics at the School of Mathematics and Statistics at the University of New South Wales, Australia. 


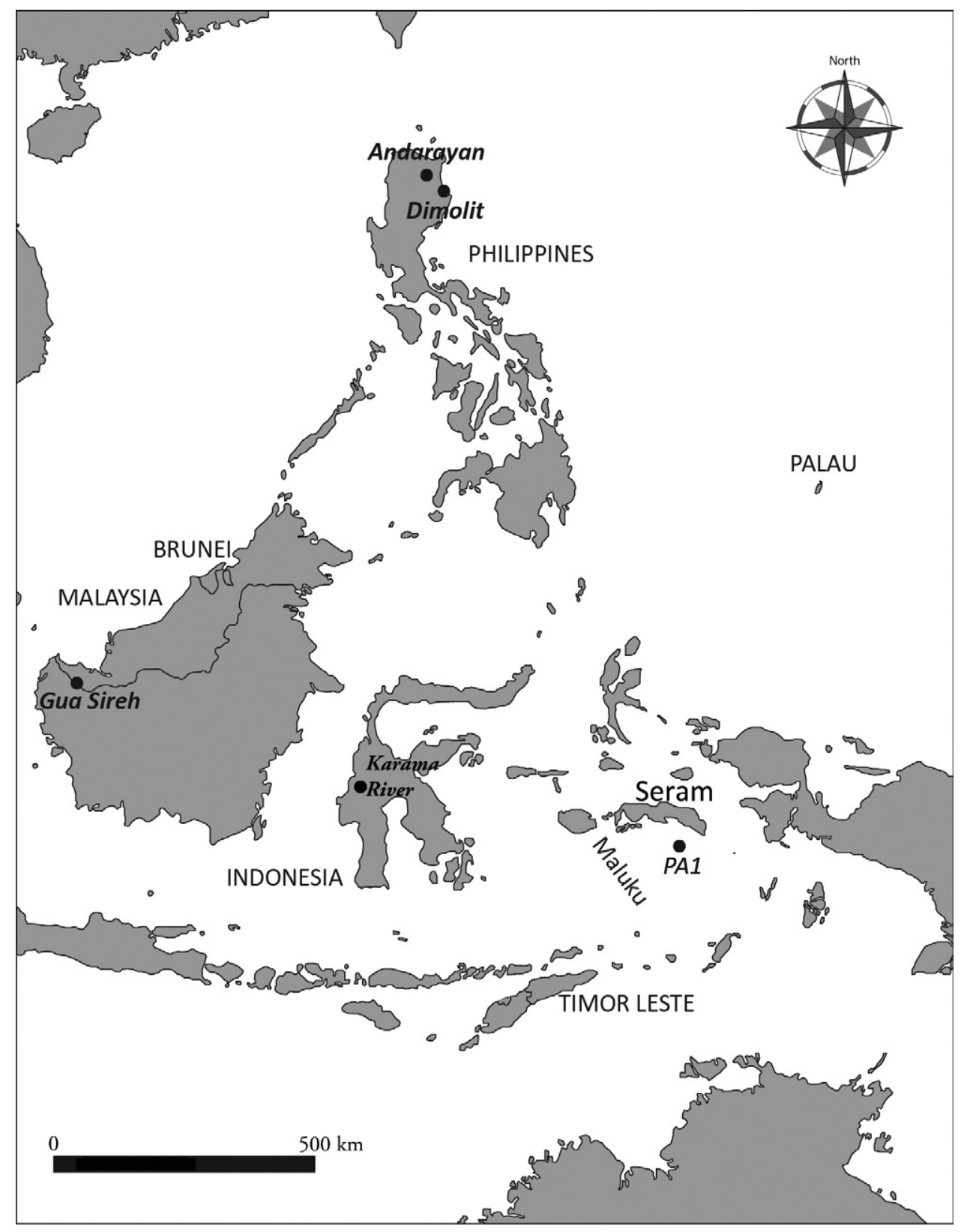

Fig. 1. Map of Island Southeast Asia showing the location of the PA1 site and other places discussed in the text.

Maluku, but seem to reflect a variety of short-term uses (Latinis and Stark 2005). The best-studied open Neolithic sites in Island Southeast Asia (ISEA) are those in the Karama valley region of South Sulawesi (first occupied ca. 3500 B.P.). They have revealed a rich array of decorated ceramics and stone tools suggesting connections with mainland Southeast Asia, Taiwan, or the Philippines (Anggraeni et al. 2014; Bulbeck 
and Nasruddin 2002; Simanjuntak 1995; Simanjuntak and Forestier 2005). The PA1 site adds to this data set and provides insight into cultural adaptations happening during the early Neolithic period in ISEA.

THE PA1 SITE

PA1 is located on the seaward edge of a limestone terrace on the southwest side of Pulau Ay, about $30 \mathrm{~m}$ in elevation (Fig. 2). Most of the southern coast of Pulau Ay consists of limestone cliffs dropping straight into the sea, but PA1 is adjacent to an erosional gully providing access between a small beach at the shore and an upland terrace (Figs. 3-5). A large shallow basin east of the site may have been a seasonal wetland before Dutch colonial period drainage canals were dug to make the area suitable for nutmeg cultivation. According to local informants, this area is still quite wet during the rainy season. Currently, this part of the island is used for shifting cultivation of cassava and bananas and is interspersed with fallow grasslands or regrowth forest. People continue to use the small beach below the site for landing small dugout fishing boats and storing fishing gear.

Lape's 1997 investigation of PA1 included a shovel test extending to sterile layers at $320 \mathrm{~cm}$ and two $1 \times 1 \mathrm{~m}$ units (Units 1 and 2) excavated to $120 \mathrm{~cm}$. Two AMS radiocarbon dates on pig bone indicated that the site was occupied by at least $3000 \mathrm{cal}$ B.P. In 2007, a joint Indonesian-US team returned to excavate a larger $2 \times 2 \mathrm{~m}$ unit (Unit 3)

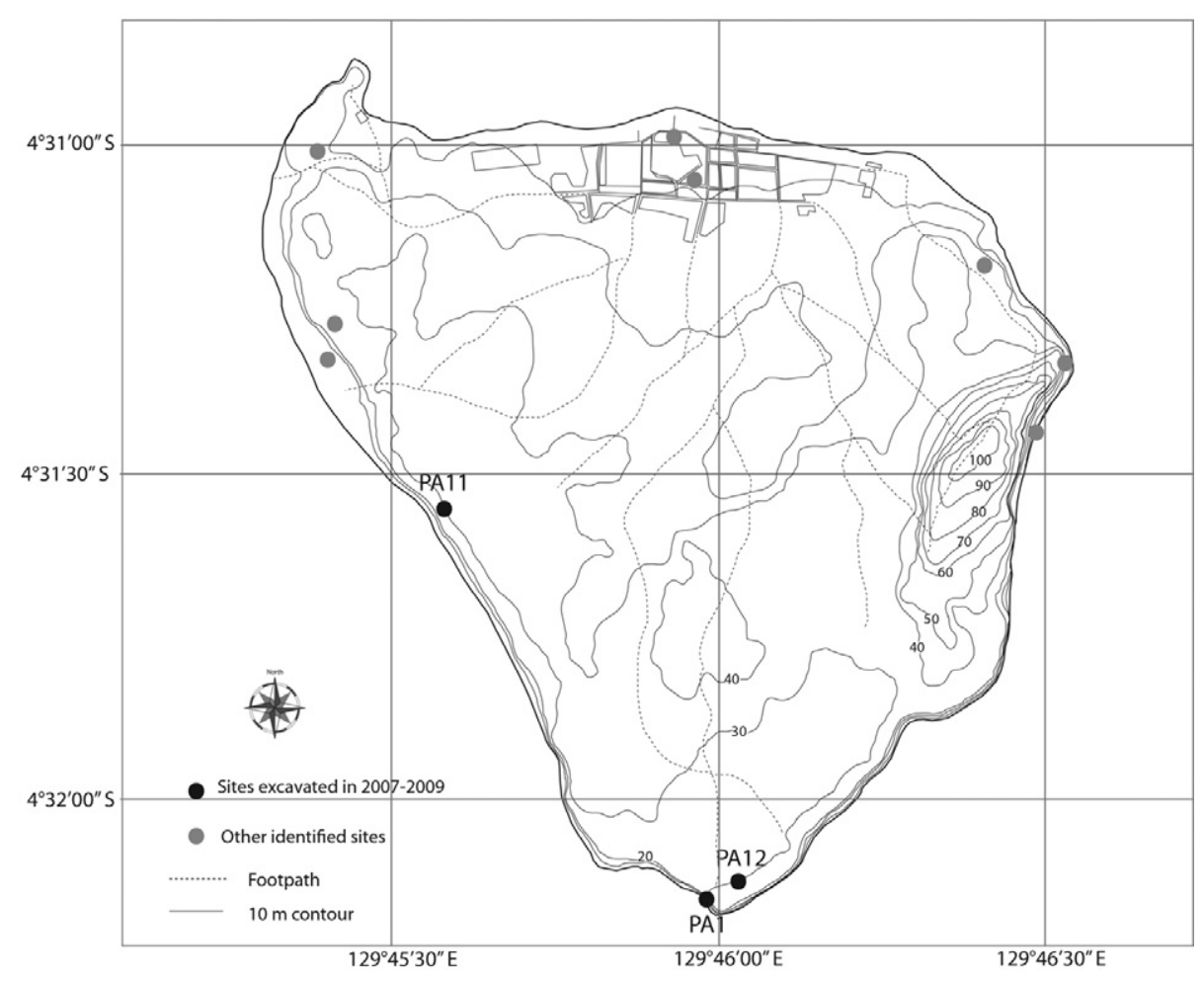

Fig. 2. Map of Pulau Ay showing locations of archaeological sites. 


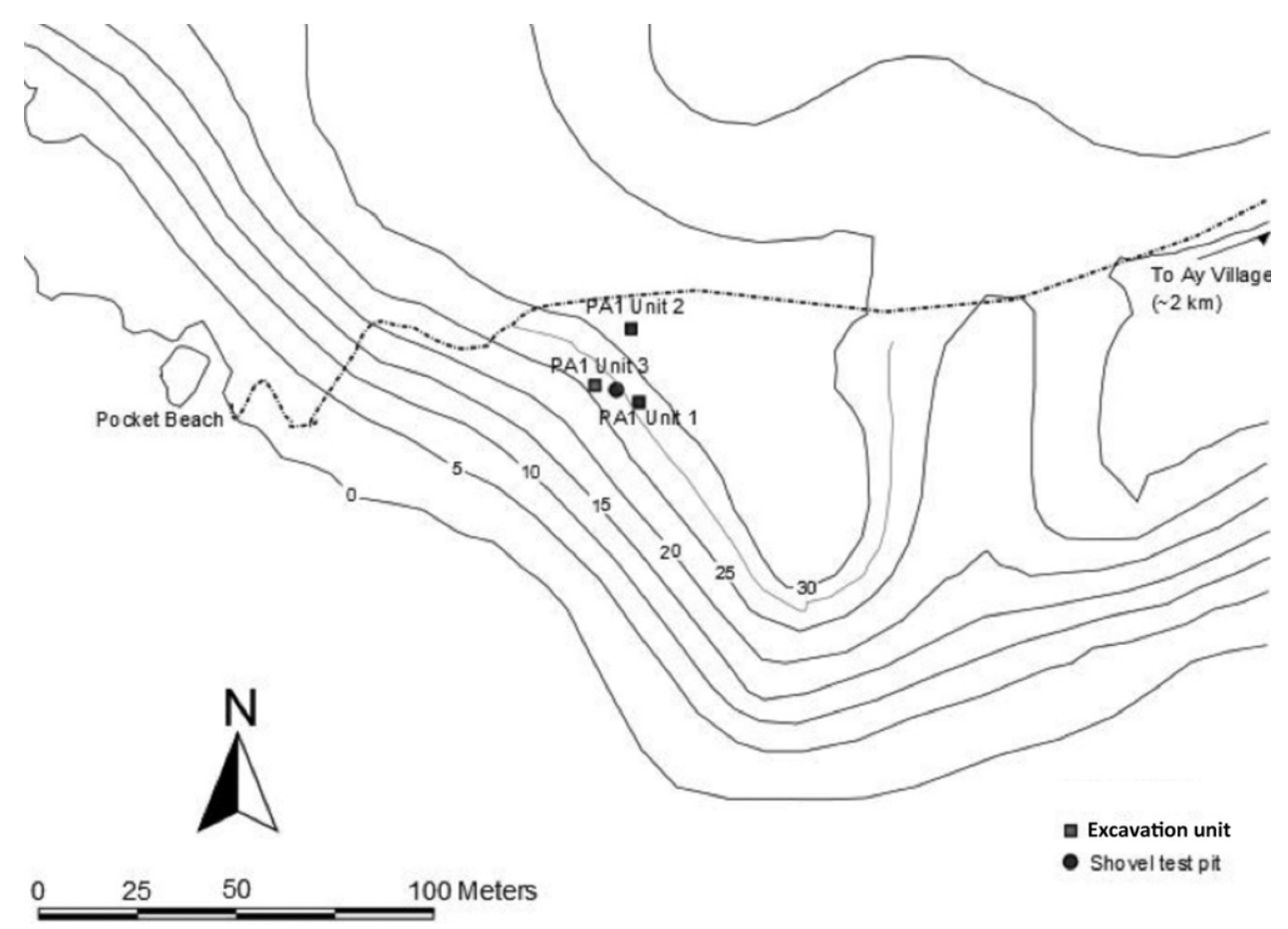

Fig. 3. PA1 site map showing excavation unit locations.

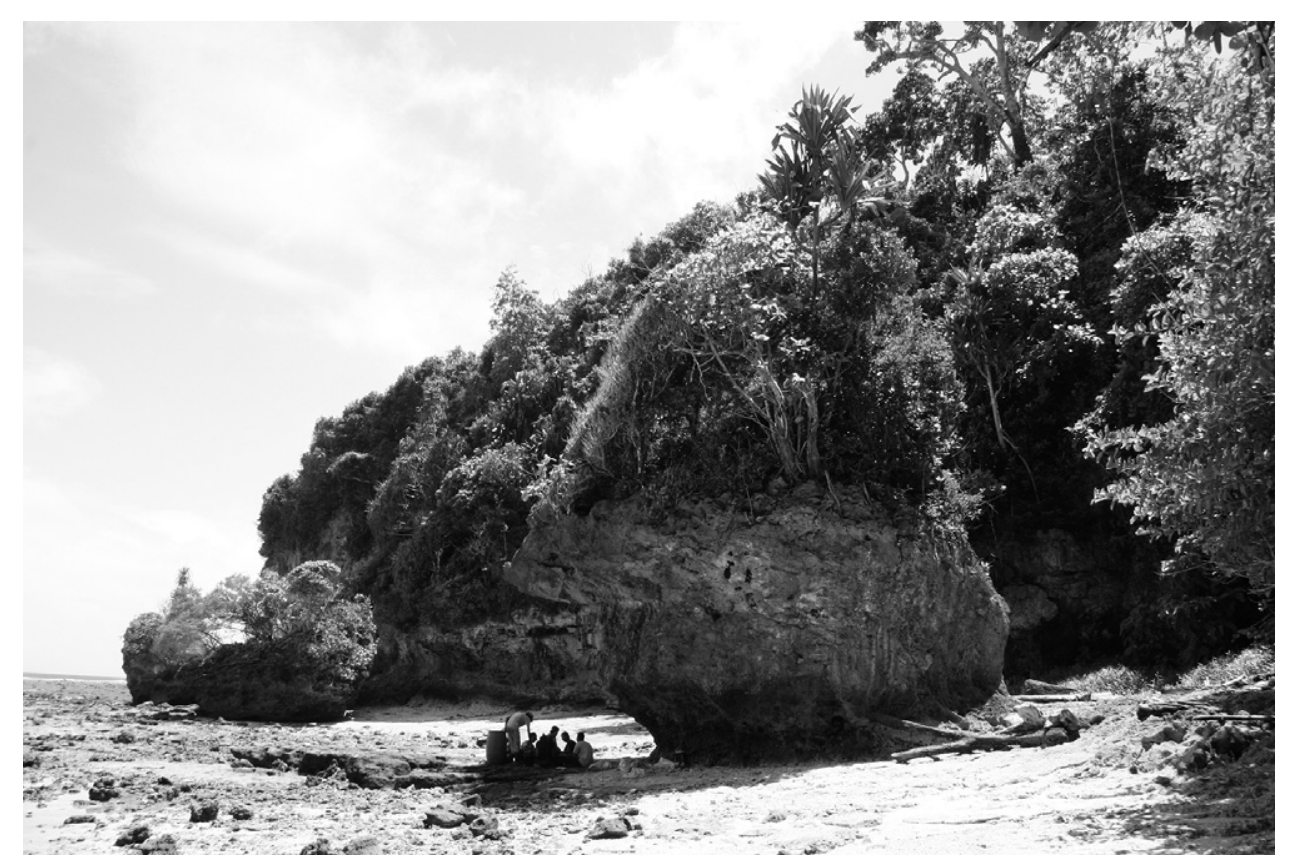

Fig. 4. Small beach below PA1 site, looking northwest (2007 photograph by Andrew Lawless). 


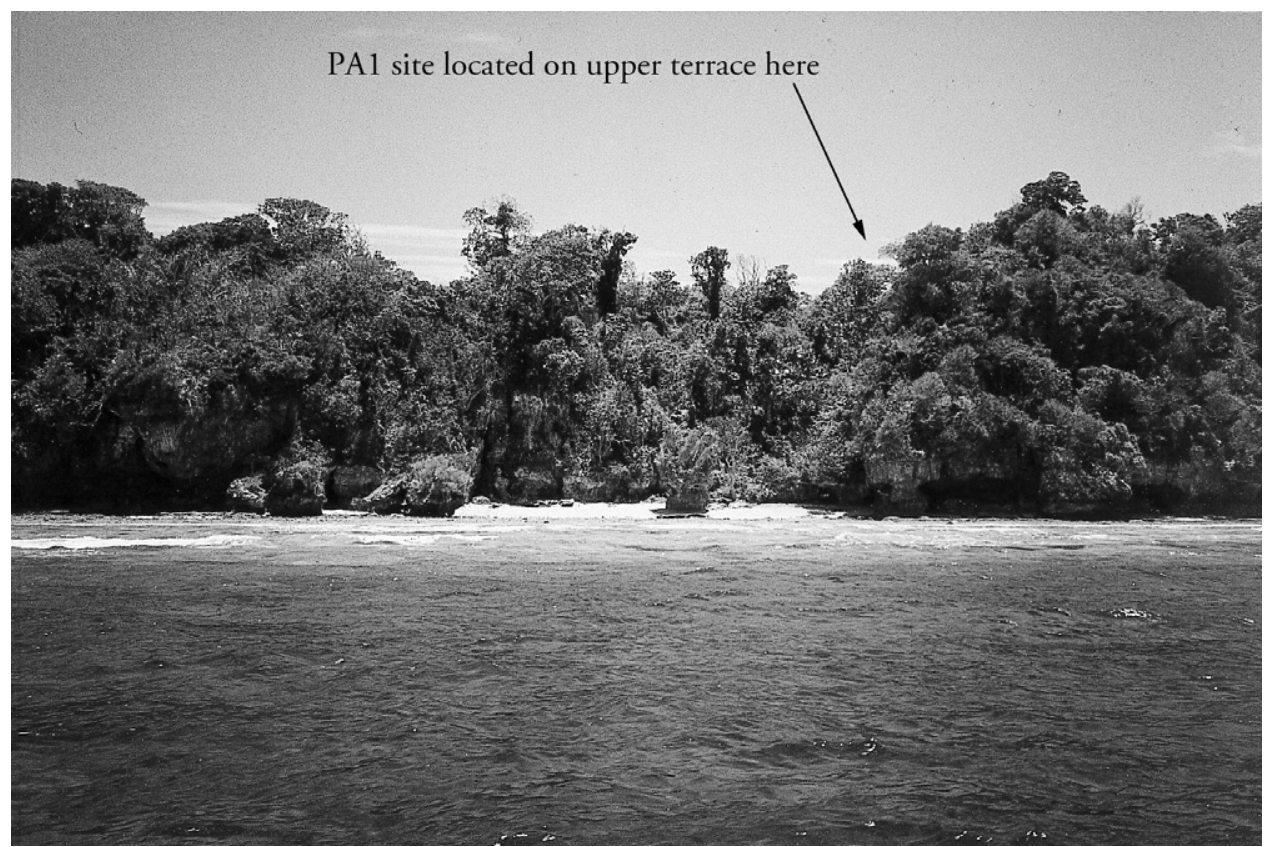

Fig. 5. View of PA1 site and small beach below, looking northeast from the sea (1997 photograph by Andrew Lawless).

down to culturally sterile layers using a fine-grained recovery method targeting archaeobotanical remains (Castillo and Fuller 2010; Oliveira 2008). Excavation followed natural strata subdivided into $10 \mathrm{~cm}$ levels, except Layer 6, which was subdivided into $5 \mathrm{~cm}$ levels (Fig. 6). Excavated sediments were dry screened through $6 \mathrm{~mm}$ mesh; finer mesh sizes were not useable due to wet, clay-rich sediments. However, 36 liter samples
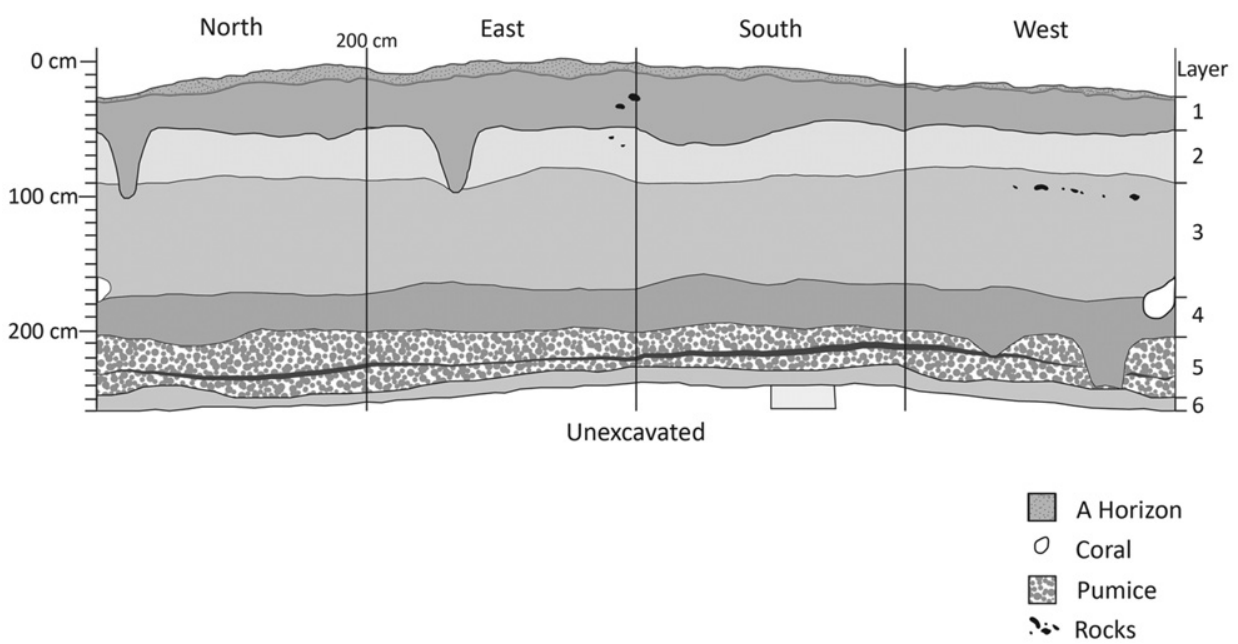

Fig. 6. PA1 Unit 3 stratigraphic profile. 
from each $10 \mathrm{~cm}$ level and feature were collected for flotation and screened through $0.2 \mathrm{~mm}$ and $1 \mathrm{~mm}$ mesh, which allowed us to recover small sized faunal remains and artifacts in the heavy fraction (described below). The excavations produced animal bone, earthenware pottery, and lithic artifacts and revealed a series of post molds suggestive of house structures. In 2009, this team returned to excavate a rockshelter, PA11, located ca. $1.5 \mathrm{~km}$ northeast of PA1, which has evidence of pre-pottery occupation beginning 7744-7536 cal B.P. The 2009 team also excavated two units at site PA12, located approximately $100 \mathrm{~m}$ east of PA1, which has similar stratigraphy to PA1, but with a possible pre-ceramic occupation deposit. Detailed results of excavations at PA11 and PA12 will be reported separately.

\section{Data And Collections Repositories}

The data underpinning the analysis reported in this article were deposited in the Open Science Framework electronic repository and are available at doi:10.17605/OSF.IO/ ESJKF (Lape 2017). Collections are curated by Balai Arkeologi, Ambon, Indonesia.

\section{PA1 Chronology}

Based on the presence of earthenware pottery, pig bones, and stone tools, along with the absence of tradeware ceramics and metal artifacts, PA1 Unit 3 Layers 2-6 assemblages were all deposited during the Island Southeast Asian Neolithic period (ca. 3500-2000 B.P.). This chronology is confirmed by AMS radiocarbon dates obtained from nine wood charcoal samples from Unit 3 (Table 1, Fig. 7). All dates are reported here as $2 \sigma$ ranges calibrated with OxCal v.4.3 (Bronk Ramsey and Lee 2013) using IntCal13 atmospheric curves (Reimer et al. 2013). The initial occupation layer (L6) at PA1 yielded two dates: 3551-3275 and 3342-3073 cal B.P. Just a few hundred years after initial occupation a major volcanic eruption from nearby Gunung Api, in the central part of the Banda group, deposited a culturally sterile pumice layer approximately $30 \mathrm{~cm}$ thick (L5). This event does not seem to have had any lasting impact on site occupation, as L4, deposited on top of sterile tephra deposits, has produced a date of 3342-3073 cal B.P. that overlaps with L6 dates.

Table i. Radiocarbon Determinations from PA1 and PA11

\begin{tabular}{|c|c|c|c|c|c|c|c|}
\hline & $\begin{array}{l}\text { LABORATORY } \\
\text { REFERENCE }\end{array}$ & LAYER & $\begin{array}{c}\text { DEPTH } \\
(\mathrm{CM})\end{array}$ & MATERIAL & $\begin{array}{c}\text { RADIOCARBON } \\
\text { AGE }\end{array}$ & $\begin{array}{l}{ }^{13} \mathrm{C} /{ }^{12} \mathrm{C} \\
\text { RATIO }\end{array}$ & $\begin{array}{l}2 \sigma \text { CALIBRATED AGE } \\
(95.4 \% \text { PROBABILITY) }\end{array}$ \\
\hline \multirow[t]{9}{*}{ PA1 Unit 3} & Beta-269220 & $2 \mathrm{~B}$ & 61 & Charcoal & $1130 \pm 40$ в.Р. & $-25.7 \%$ & 1174-960 в.Р. \\
\hline & Beta-277826 & $2 \mathrm{D}$ & 86 & Charcoal & $2640 \pm 40$ в.Р. & $-24.7 \%$ & $2846-2727$ в.P. \\
\hline & Beta-235454 & $3 \mathrm{C}$ & 105 & Charcoal & $2460 \pm 40$ в.Р. & $-23.5 \%$ & 2711-2365 в.P. \\
\hline & Beta-302404 & $3 \mathrm{E}$ & 124 & Charcoal & $2780 \pm 30$ в.Р. & $-23.7 \%$ & 2954-2794 в.P. \\
\hline & Beta-302405 & $3 \mathrm{I}$ & 164 & Charcoal & $2880 \pm 30$ в.Р. & $-24.1 \%$ & 3142-2889 в.P. \\
\hline & Beta-304478 & $3 \mathrm{I}$ & $175-185$ & Charcoal & $2940 \pm 40$ в.Р. & $-26.4 \%$ & 3211-2968 в.P. \\
\hline & Beta-240738 & $4 \mathrm{~B}$ & 195 & Charcoal & $3010 \pm 40$ в.Р. & $-24.5 \%$ & 3336-3078 в.P. \\
\hline & Beta-240739 & $6 \mathrm{~A}$ & 250 & Charcoal & $3190 \pm 40$ в.Р. & $-28.5 \%$ & 3550-3341 в.P. \\
\hline & Beta-235453 & $6 \mathrm{~B}$ & 236 & Charcoal & $3010 \pm 40$ в.Р. & $-24.8 \%$ & 3336-3078 в.P. \\
\hline PA11 Unit 1 & Beta-298970 & $6 \mathrm{P}$ & 170 & Marine shell & $7160 \pm 50$ в.Р. & $+2.3 \%$ & 7744-7536 cal в.P. \\
\hline
\end{tabular}




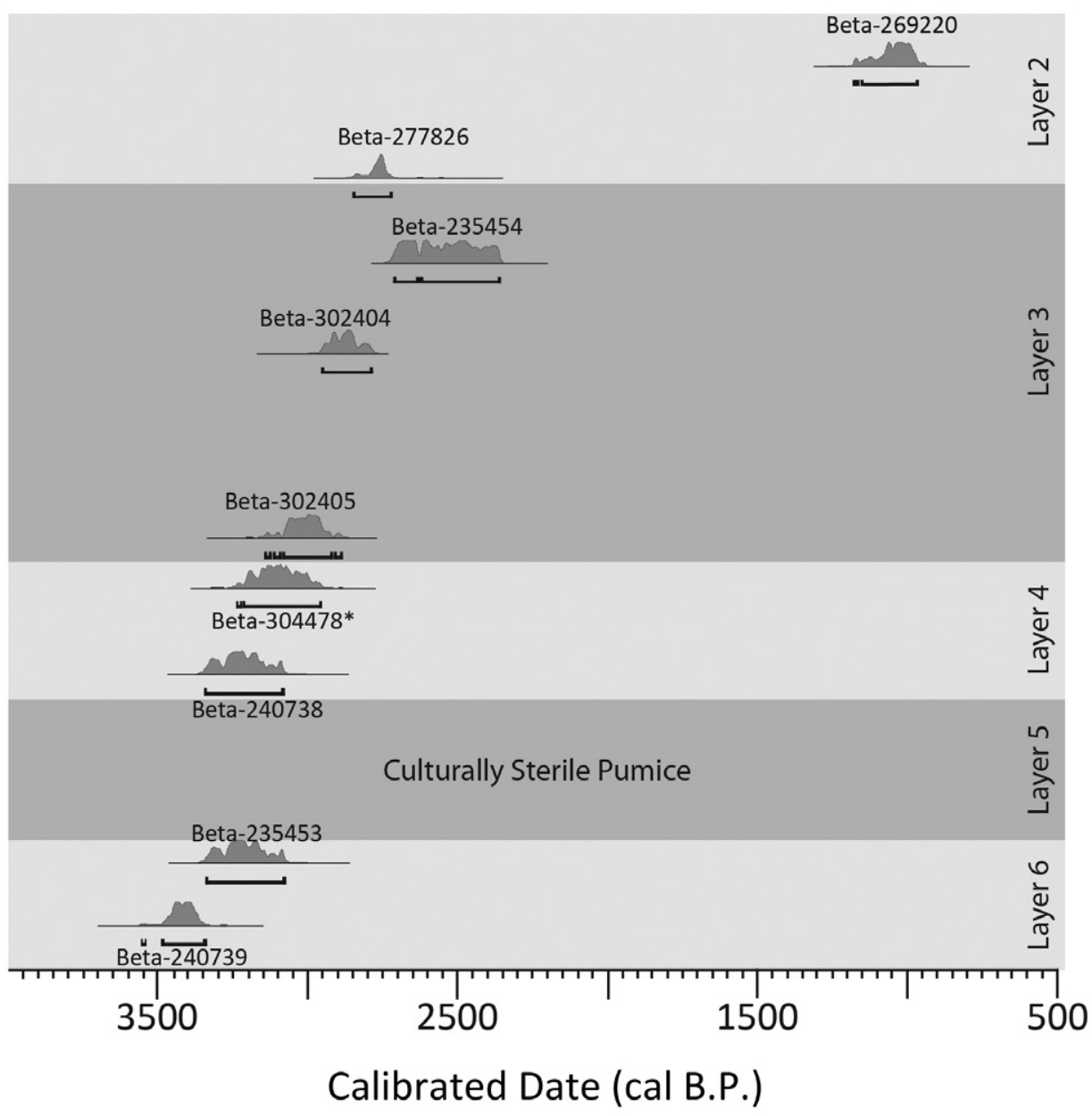

Fig. 7. Plot of calibrated AMS dates from PA1 Unit 3. *Beta-304478 sample was recovered from flotation; depth is approximate.

One of the nine dates is slightly out of sequence. The inversion of dates from L2D and $\mathrm{L} 3 \mathrm{C}$ is the only indication of disturbance in the PA1 stratigraphic sequence. The charcoal sample from L2D was probably displaced when post holes were dug. Cultural deposition at the site continued until the late precolonial period. L1 produced a lead bullet, presumably from the Dutch colonial period, but no other artifacts recovered from the site (including the 1997 excavations) indicate occupation after 1000 B.P., when tradewares from mainland Asia begin to appear at other sites in the Banda Islands. Early seventeenth century Dutch maps show a village named Leitsa or Leytsa in the vicinity of PA1 (Lape 2002), but this was probably located several hundred meters to the east of the site where grave markers and tradeware artifacts are visible on the surface today.

A change in site use or possibly a hiatus in site occupation is apparent sometime during the 2300-1000 B.P. period. The depositional rate in L2 is much slower than that represented in L3-L6 (Fig. 7). Interestingly, this potential hiatus in occupation at PA1 
coincides with a period of site abandonment at the contemporary site of Minanga Sipakko, Kalumpang, Sulawesi (Bulbeck and Nasruddin 2002) as well as a lack of radiocarbon dates from this time period from a recent survey on East Seram (Lape et al. 2017).

\section{POTTERY}

Earthenware sherds were abundant in all cultural layers at PA1, but no complete or restorable vessels were encountered (Fig. 8). A sample $(n=684)$ of rim and decorated body sherds from the site were analyzed for technological characteristics and style by Shiung (see Shiung 2011 for further details). Analysis of this earthenware reveals clear differences between the early layers L6-L4 (predating 3000 B.P.) and later layers

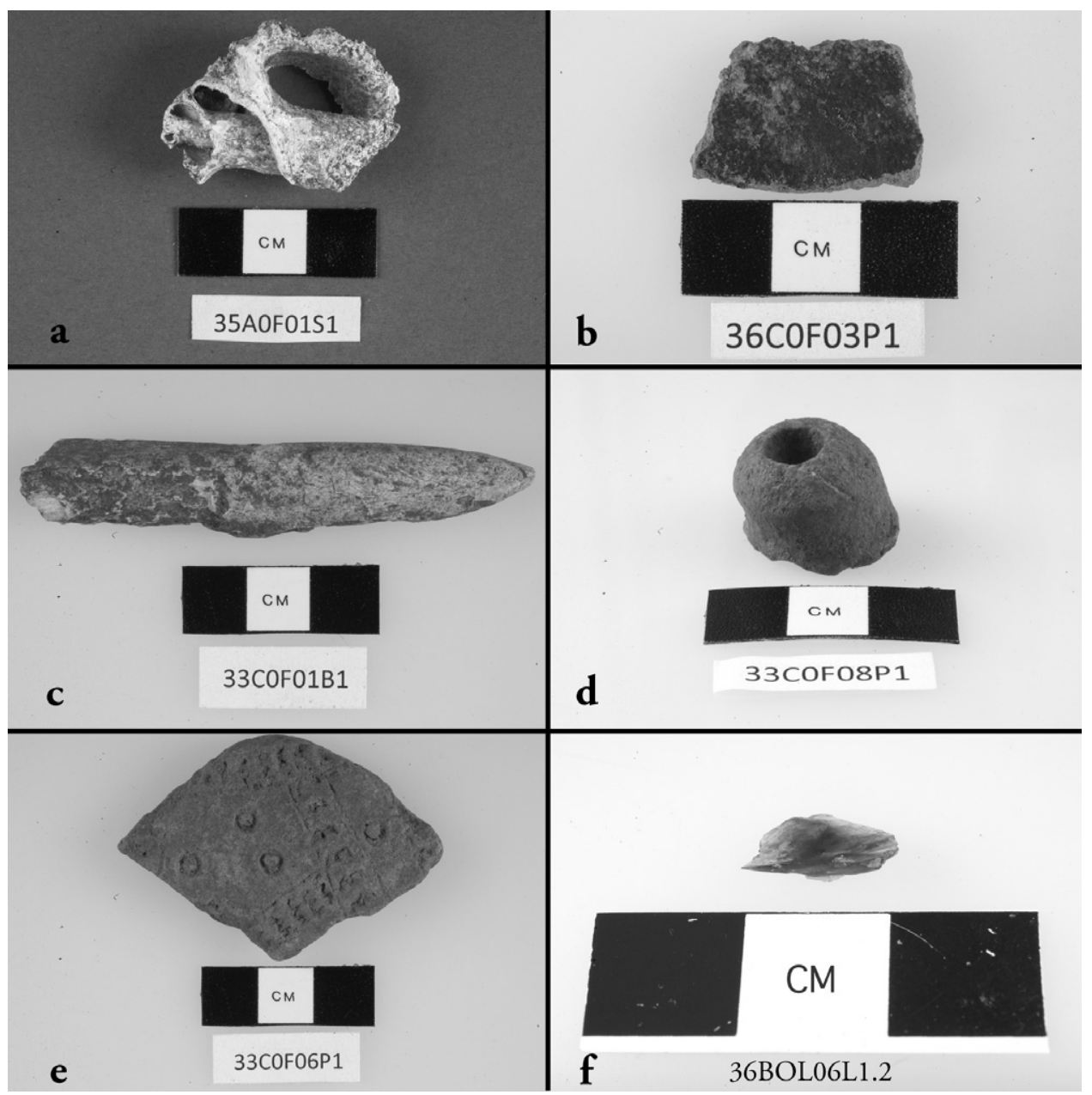

Fig. 8. Artifacts from PA1 Unit 3: (a) shell from bottom of layer 5A; (b) red slip earthenware from layer 6C; (c) bone point from layer 3C; (d) earthenware spout (?) fragment from layer 3C; (e) circle stamped earthenware pottery from layer $3 \mathrm{C}$; (f) obsidian from layer $6 \mathrm{~B}$. 
L3-L2 (Fig. 9). In the earliest layers, pottery tends to be thin-walled with fine-grained plagioclase and pyroxene tempers. Vessels typically have long, everted rims and red slips are common either on the interior or both surfaces. Burnishing was more common in L6 than in any subsequent deposit (e.g., Fig. 8b). Decoration was rare but some early sherds exhibited incised geometric patterns just below the rim. Most L6 sherds were either fully oxidized or oxidized at the exterior with a reduced core, indicating an open firing environment and short firing duration. Later in the sequence, reduced cores are less common, suggesting that vessels were fired longer.

Pottery from later levels at PA1 is thicker walled, with mean rim thickness increasing within rim form categories and new, shorter rim forms appearing. Temper is coarser and, while plagioclase and pyroxene remain common, quartz tempers become more common over time (Table 2). Everted rims are also common in later layers but the dominant form shifts from everted convex rims with curled or pointed lips to everted straight rims with curled, pointed, or flattened lips. The frequency of red slip drops significantly between layers 4-6 and layer 3, from over 40 percent to under 20 percent (Table 3). Burnishing is also rare in later period earthenware. Decoration remains infrequent throughout the sequence. Dentate stamping and appliqué in particular are too rare for any meaningful pattern to be identified. A single impressed shell and a circle-stamped sherd show stylistic affinities with circle stamped pottery from Sulawesi and the Philippines (Fig. 8e). However, the fact that only one such sherd was recovered, as well as the general paucity of decorated sherds below L2, suggests that stylistic traditions were not intensely shared between Pulau Ay and these areas.

The observed patterns of change over time in earthenware characteristics indicate a shift in function for pottery. The early, thinner walled vessels with long everted rims suggest that storage was the primary function of earthenware vessels. The tendency toward longer everted rims is indicative of liquid storage as long-necked vessels would

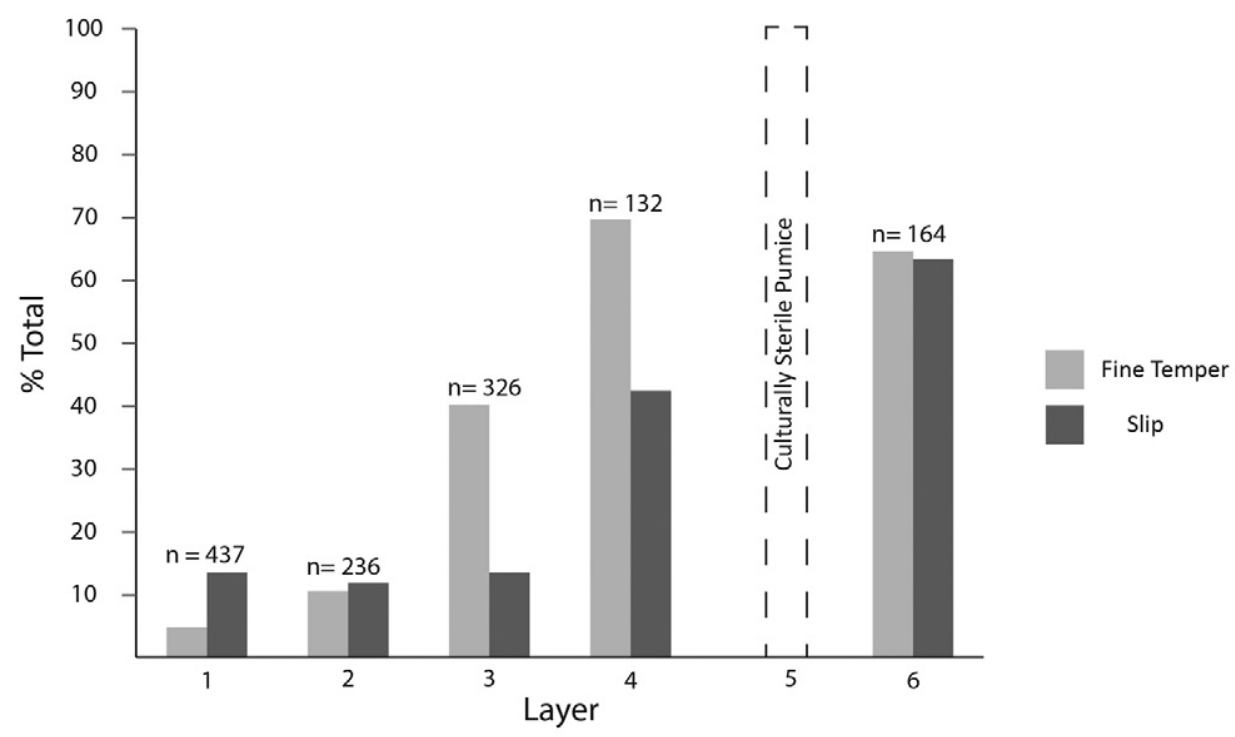

Fig. 9. Change in frequency of the presence of fine temper and slip (not mutually exclusive categories) in PA1 Unit 3 earthenware pottery by stratigraphic layer. 
LAPE ET AL. - NEW DATA FROM A NEOLITHIC SITE IN EASTERN INDONESIA 23 I

Table 2. Frequencies/Percentages of Earthenware Temper Grain Sizes at Pa1 Unit 3

\begin{tabular}{llllllr}
\hline LAYER & FINE & MEDIUM & COARSE & FINE + MEDIUM & COARSE + MEDIUM & TOTAL \\
\hline 1 & $11 / 6$ & $26 / 13$ & $145 / 74$ & $3 / 2$ & $20 / 5$ & 196 \\
2 & $10 / 9$ & $11 / 10$ & $76 / 68$ & $12 / 11$ & $3 / 3$ & 112 \\
3 & $100 / 40$ & $49 / 20$ & $17 / 7$ & $75 / 30$ & $8 / 3$ & 245 \\
4 & $51 / 75$ & $8 / 13$ & $0 / 0$ & $7 / 12$ & $0 / 0$ & 66 \\
6 & $70 / 100$ & $0 / 0$ & $0 / 0$ & $0 / 0$ & $0 / 0$ & 70 \\
\hline
\end{tabular}

Fine: $<2 \mathrm{~mm}$; medium: $2-5 \mathrm{~mm}$; coarse: $>5 \mathrm{~mm}$.

Table 3. Frequencies/Percentages of Earthenware Surface Treatments at Pa1 Unit 3

\begin{tabular}{lllr}
\hline LAYER & SLIP & NON-SLIP & TOTAL \\
\hline 1 & $48 / 24$ & $148 / 76$ & 196 \\
2 & $22 / 21$ & $85 / 79$ & 107 \\
3 & $33 / 13$ & $212 / 87$ & 245 \\
4 & $28 / 42$ & $38 / 58$ & 66 \\
6 & $46 / 66$ & $24 / 34$ & 70 \\
\hline
\end{tabular}

reduce spillage of water or other fluids (Shiung 2011). The shift to thicker-walled, shorter-rimmed, coarse-tempered pottery in later periods could indicate that pottery was increasingly used for cooking in addition to storage. Coarse temper is known to increase thermal shock resistance (Tite et al. 2001).

\section{LITHICS}

Lithic artifacts were almost entirely small $(<1 \mathrm{~cm})$, chipped chert scrapers, or debitage. A total of 16 small obsidian scrapers or debitage were recovered from L3C-L6 (Fig. 8f). These were submitted to Matthew Spriggs and Christian Reepmeyer at the Australian National University for geochemical analysis using LA-ICP-MS. Their results indicated that all 12 were from a single source, but did not match any known source in ISEA or Oceania (Reepmeyer et al. 2011). The PA1 debitage also did not match dacitic glass from Banda Neira. Gunung Api, Banda remains a possible source, but dacites from this source analyzed by Jezek and Hutchison (1978) had much lower $\mathrm{SiO}_{2}$ (63.84-67.43 wt\%) than reported by Reepmeyer and colleagues (2011) for PA1 samples (mean $75.7 \mathrm{wt} \%$ ). The small size and relative paucity of obsidian at PA1 also suggest that the source was not local. Chert is available in the Banda Islands; we identified an outcrop of dark grey colored chert on Palau Rhun, due west of the PA1 site. However, the red color of the PA1 chert appears a closer match with the abundant cherts of the southeastern part of Seram Islands, $100 \mathrm{~km}$ northeast of PA1. Sourcing of the PA1 chert remains speculative.

FAUNA

Excavations at PA1 Unit 3 yielded 14,338 animal bone fragments that were analyzed by Peterson (see Peterson 2015 for details). Bone and tooth fragments from both the $6 \mathrm{~mm}$ 
excavation screens and the heavy fraction from flotation $(>1 \mathrm{~mm})$ were examined and classified as mammal, fish, or bird. Further identification (element and taxon) was attempted for all mammal bone and tooth fragments. Due to heavy fragmentation, only 15 percent of the 3590 mammal bone fragments could be identified to genera or better. Mammalian fauna were identified by Peterson using comparative collections housed at the Burke Museum of Natural History and Culture at the University of Washington. Taxonomic identification of fishbone has not yet been undertaken.

Faunal remains from PA1 Unit 3 indicate a strong marine orientation. Fish bone, mostly very small-sized, is more abundant than mammal bone and comprises 75 percent of the total assemblage. Only a handful of bird bone was recovered $(\sim 0.1 \%)$. Although fish bone is present in all levels, the proportion of fish and mammal bone varies between stratigraphic layers. Figure 10 shows the percentage of mammal and fishbone by layer, revealing a change in the composition of the assemblage over time. In the earliest Neolithic layer (L6), mammal bone is all but absent $(n=54)$, while fish is very abundant $(n=2548)$. Despite these strong indications of marine-oriented subsistence at PA1, shell was absent from all layers except at the boundary between layers 5A and 6A, immediately below the pumice deposit (Fig. 8a). These were columella from marine gastropods, but preservation was poor and none could be positively identified. The absence of shell from other layers at PA1 likely reflects a preservation bias. Shell was comparatively well represented at the nearby and contemporaneous PA12, where 17 different taxa of small to medium-sized, shallowwater, reef-dwelling gastropods were identified. At PA12, eight families account for at least 1 percent each of the total identifiable specimens. In order of abundance these are: Conus, Muricidae, Turbo, Cypraea, Trochus, Tridacnidae, Neritidae, and Angaridae.

Of the three domesticates typically present in Neolithic sites in ISEA, only Sus scrofa and Canis familiaris were identified at PA1, where they account for nearly all of the

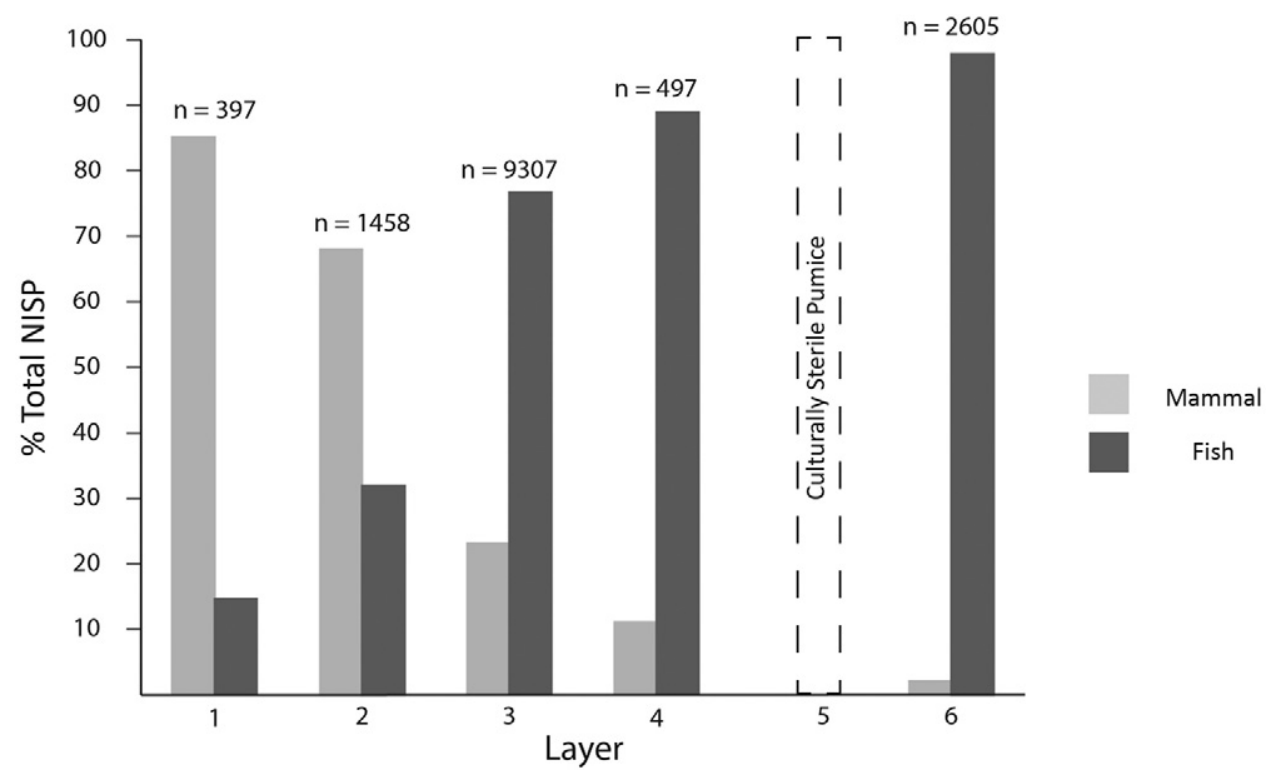

Fig. 10. Relative abundance of terrestrial and marine fauna by stratigraphic layer. 
identifiable mammal bone. This is not surprising given the island's impoverished terrestrial fauna. Aside from domesticates, Pulau Ay had few native species, probably including rodents, a small varanid lizard, and possibly Phalanger orientalis. The latter is present on the island today, but may have been translocated by humans. Phalanger orientalis was not identified in the PA1 faunal assemblage and it is currently unknown how long the species has been present in the Banda Islands.

Domesticated dog, while present, is rare with a total NISP (number of identified specimens) of only 14, nearly all of which were recovered from L4A-L3C. Only 4 specimens from L6 were identified as Sus scrofa, indicating that pig only became an important subsistence resource several hundred years after initial occupation. Sus scrofa abundance mirrors the general trend toward a greater dependence on terrestrial mammals (Fig. 10). Murid rodents are present in the faunal record of the site, but are very rare during the early period of site occupation. Nearly all identifiable Muridae specimens were from the heavy fraction $(>2 \mathrm{~mm})$ of flotation samples. As these terrestrial mammals increase in abundance in more recent layers, fishbone abundance declines, indicating a general trend towards greater dependence on terrestrial resources over time. Screening all sediments through smaller mesh would have resulted in larger NISP for both this taxon and for fish.

Like many sites in ISEA, bone preservation at PA1 is relatively poor, although perhaps somewhat better than at typical tropical Pacific island sites. It is intriguing that shell preservation also seems to have been quite poor at PA1, since it is located adjacent to a productive coral reef and nearby Neolithic sites had much larger assemblages of shell. We do not have a good explanation for this. The possibility that the observed pattern of the mammal versus fish bone is the result of post-depositional processes or recovery bias rather than reflecting a difference in site use over time must be considered. Bone diagenesis is a complex process dependent on many factors, but the degree of fragmentation is relatively consistent over time at this site, making it unlikely that preservation favored fishbone in the earliest phase and mammal bone at a later time.

\section{FLORA}

As mentioned above, the 2007 excavations at PA1 were oriented toward the recovery of archaeobotanical remains because we currently know very little about which flora were incorporated into human diets in ISEA during the period when PA1 was first occupied. The project attempted to recover and identify both macrobotanical and microbotanical (starch) remains. Four 9-liter samples were collected for flotation from each $10 \mathrm{~cm}$ level, one from each $1 \times 1 \mathrm{~m}$ quadrant of the $2 \times 2 \mathrm{~m}$ PA1 Unit 3 excavation unit. Sediments were air-dried and then floated manually using a $0.2 \mathrm{~mm}-$ mesh sieve to skim floated materials and a $1.0 \mathrm{~mm}$-mesh sieve to capture heavy materials. Lee supervised the sample collection and flotation in the field and conducted macrobotanical analysis of the resulting total of 44 flotation samples (394 liters of sediment). Macroscopic plant remains were extremely rare; unfortunately, none were positively identified. Over 2200 charred termite fecal pellets were identified, including one found below the pumice layer L5, which was unlikely to be an intrusion from younger layers above (Fig. 11). Termite fecal pellets could be introduced into the site in several ways. Termites may have been present in felled trees or buried roots that were present at different periods during and subsequent to site occupation. Termite-infested palms or trees brought in for fuel may have provided another avenue for pellets to enter 


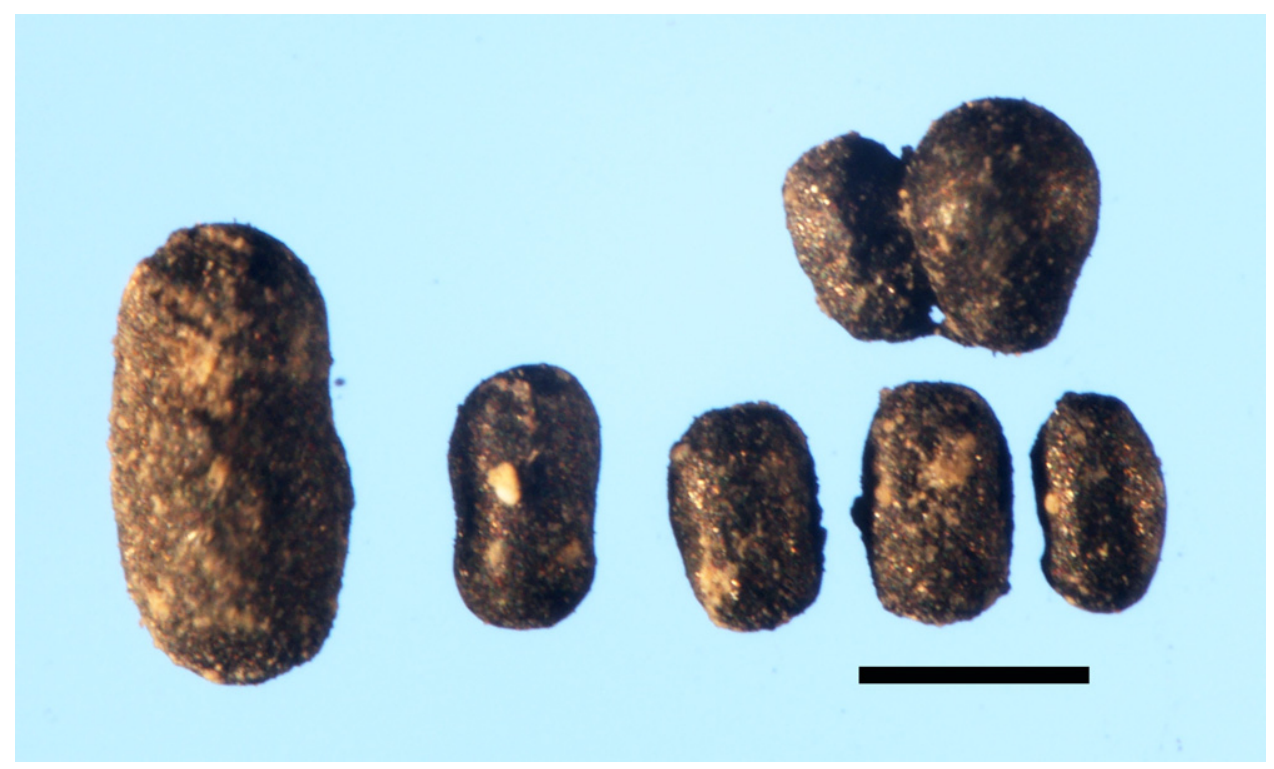

Fig. 11. Termite fecal pellets recovered from Layer 3I (southeastern quadrant), scale $500 \mu \mathrm{m}$.

the site (Adams 1984). A grass short cell bilobate phytolith was observed in the crosssection view of one pellet recovered from Layer 3, but its species is unidentifiable as many grass taxa have similar phytoliths (Fig. 12).

Starch residues related to plant processing and use are known to survive thousands of years in a variety of contexts ranging from the arid zone to the tropics (Cosgrove et al. 2007; Field 2008; Field et al. 2016; Fullagar et al. 2006; Piperno et al. 2004; Summerhayes et al. 2010). A pilot study was undertaken to determine whether or not identifiable starch grains were preserved as residues on the earthenware sherds recovered during excavation. The mechanisms responsible for their preservation are still largely unknown.

Eleven potsherds were specially handled in the field to reduce the possibility of contamination. They were submitted for starch analysis by Field using standard methods: ultrasonication, centrifugation, and heavy liquid separation (specific gravity: 2.35), followed by mounting in 50:50, glycerol:water (Field et al. 2016). Total slide counts were obtained with a Zeiss Axioskop II microscope fitted with Nomarski optics, a $63 \times$ oil immersion objective, and a $1.6 \times$ magnifier (Fullagar et al. 2006). Images were collected with a Zeiss $\mathrm{HrC}$ digital camera and Zeiss Axiovision software.

All 11 potsherds yielded starch grains. The number of grains identified ranged from 5 to 29 per sherd. A total of 135 starch grains were recovered, of which 129 were suitable for digitizing for analysis using the starch identification methods recently developed by Coster and Field (2015). Some of the grains were not traced for the study because of physical damage that had disrupted the margins. A reference set of potential starchy plant contributors was compiled based on available herbarium records and consultation with the site investigators (Table 4). 


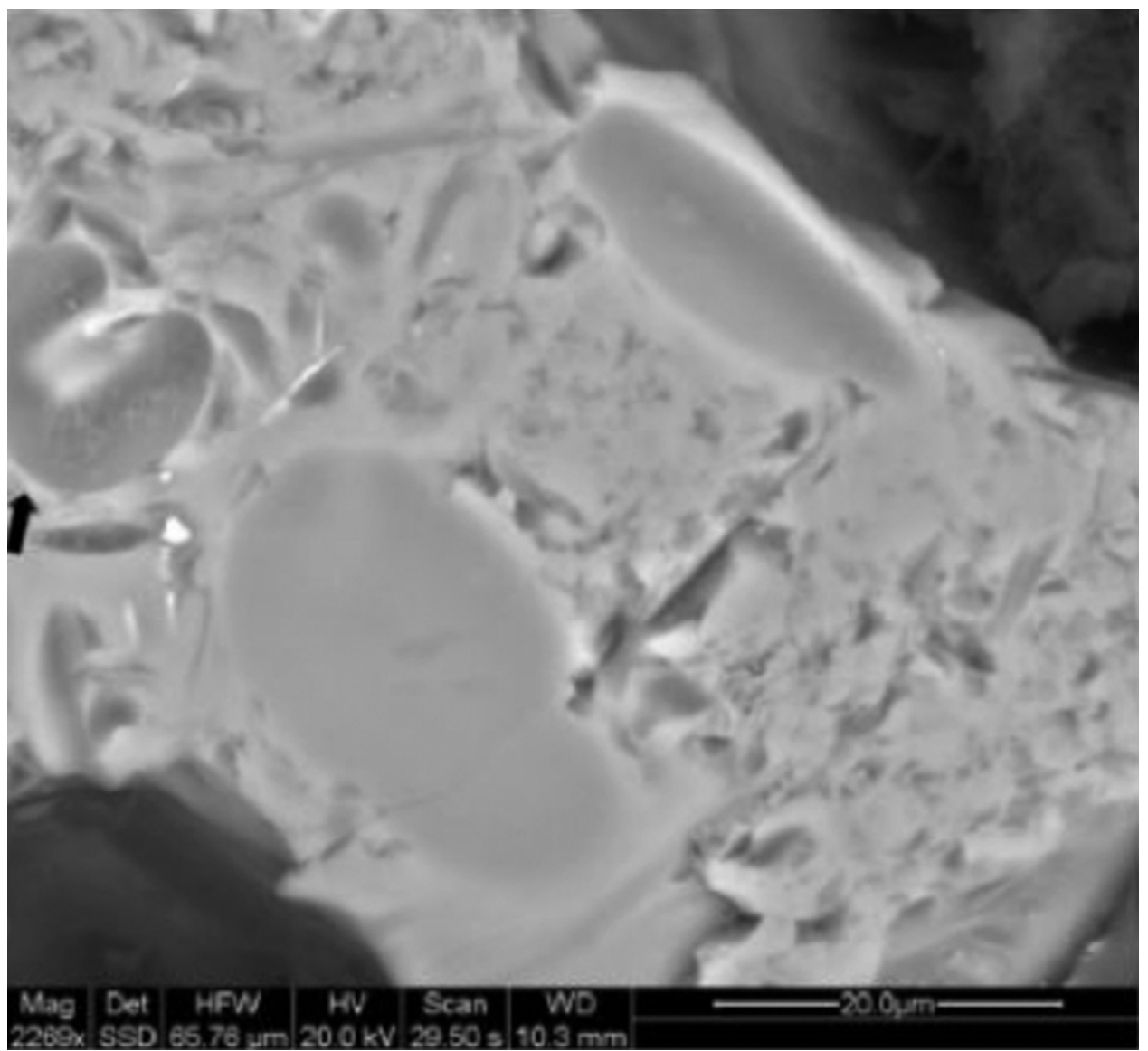

Fig. 12. SEM image of termite fecal pellet in cross section showing phytolith (arrow).

Table 4. Starch Grain Reference Sources

\begin{tabular}{lll}
\hline SPECIES & COMMON NAME & REFERENCE SOURCE \\
\hline Dioscorea alata & Purple yam & Papua New Guinea (PNG) \\
Dioscorea bulbifera & Air potato/bitter yam & PNG/Australia \\
Dioscorea esculenta & Lesser yam & PNG \\
Dioscorea pentaphylla & Five-leaf yam & PNG \\
Metroxylon sagu & Sago & PNG \\
Musa acuminata & Banana & PNG \\
Myristica fragrans & Nutmeg & Banda Islands \\
\hline
\end{tabular}

The starch grains identified from the ceramic sherds included Dioscorea alata, Dioscorea bulbifera, Metroxylon sagu, and Myristica fragrans. The survival of starch grains from the PA1 site and identification to plant taxa demonstrates the potential of this method for investigating early Neolithic horticultural practices. The presence of 
Myristica fragrans and other species listed above were determined using a geometric morphometric method, which effectively translates to shape analysis of the starch grains (Coster and Field 2015; Field et al. 2016). The geometric morphometric measures of the starch grains of unknown plant taxa (pot sherd residues) were used in combination with an appropriately curated modern reference collection to infer the probable species of origin (Coster and Field 2015). The modern comparative reference set included Colocasia esculenta (458), Dioscorea alata (199), Dioscorea bulbifera (343), Dioscorea esculenta (284), Dioscorea pentaphylla (146), Metroxylon sagu (101), Musa acuminata (94), Myristica fragrans (120), and Oryza sativa (143) (the number of individual grains examined noted in parentheses).

The characteristics, or predictor variables, calculated for the starch grains were the hilum position as an offset from the center of mass of the grain, perimeter, area, maximum length through the hilum, and the Fourier signature of the grain outline-a decomposition of the shape into its principle components (Coster and Field 2015). These predictor variables were used to build a classifier for a reference species set against which the unknown grains were tested. It has been estimated that the within-species variations should be adequately represented by approximately 100 grains. Different classifiers employing all combinations of the predictor variables were assessed to find an optimal classifier for the reference set (Coster and Field 2015). In this case, it was a quadratic classifier based on subgroups of the reference species, with a voted output for the predictor variables area, perimeter, circularity, and Fourier signature (components $0-6)$.

The optimal classifier also divided the reference species measurements into subsets, which accounted for intra-species variability and orientation (within the slide mounting media), and recombined the output using a vote algorithm for the final prediction (Coster and Field 2015). The dendrogram in Fig. 13 shows the distance between the species across these predictor variables. It demonstrates that separation and prediction using these predictors is feasible.

The classifier performance was assessed for true/false positive and negative rates upon re-substitution of the original training set and also by 50 -fold cross-validation where subsets of the training set were withheld and the classifier recreated and tested for performance on the withheld subset (Coster and Field 2015). A reverse cross-fold validation error (CVE) was determined measuring the predictions that were not actually from that grain species.

The results for the predictions were then assessed according to the two confidence measures (dendrogram and confusion matrix) (Fig. 14). The unknown grains were then visually assessed by an expert starch analyst (Field). The unknown grain was compared to those grains in the reference set that were the closest match across the predictor variables. The visual assessment took categorical and subjective attributes of the grains such as position of the hilum, presence or absence of lamellae, and other surface features into account as well as the CVE confidence and a positive prediction value based on the CVE for the species with that prediction score.

Each prediction was assessed as validated, probable, a false positive, or not represented in the reference species. The predictions were further classified according to the confidence via the prediction score output from the classifier. The resubstitution errors from the reference grains were used to assess the distributions of true and false positives for the training set and the proportion of true positives (referred to as PPV) for that species was calculated. Cutoffs for this were set at 70 percent, 80 percent, 


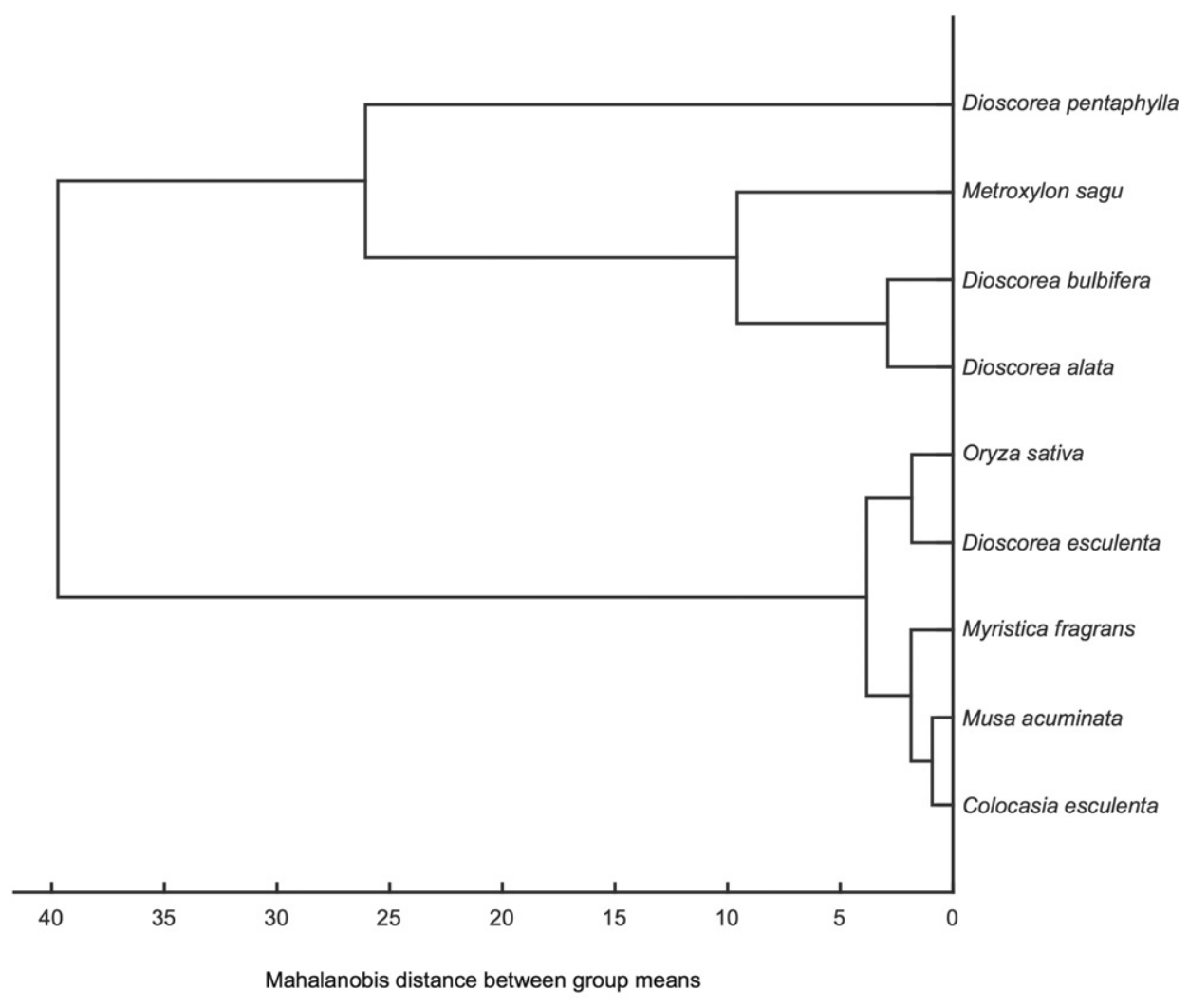

Fig. 13. Dendrogram indicating the separation of the target starch reference species based on a quadratic classifier.

and 90 percent and the corresponding prediction scores determined. If the prediction score corresponded to PPV $>0.9$, the entry is a confident prediction. If the prediction score corresponds to $0.8<\mathrm{PPV} \leq 0.9$, then the prediction is probable. If the prediction score corresponds to $0.7<\mathrm{PPV} \leq 0.8$, then the prediction is likely. Classifications with scores corresponding to PPE $\leq 0.7$, did not appear (although possibly present). The cross-fold validation confidence for the predicted species also needs to be taken into account in the results assessment. The unknown grains listed in Table 5 were identified as Myristica fragrans, although not all were confident predictions. The prediction species reverse cross fold validation was on the high side for this species at 0.35 , but some of the prediction scores were extremely high also. The conservative nature of this analysis meant that it is likely that more grains were present from Myristica fragrans, but could not be confidently attributed to taxa.

It is important to note that this analysis focused on creating a highly confident measure of the presence of a particular species (true positive), rather than the assessment of abundance across different species. The remarkable preservation of the starches on pottery from L6 and L3 could indicate exploitation of wild plants or the presence of cultivars. The exact timing and locus of domestication are unknown for 


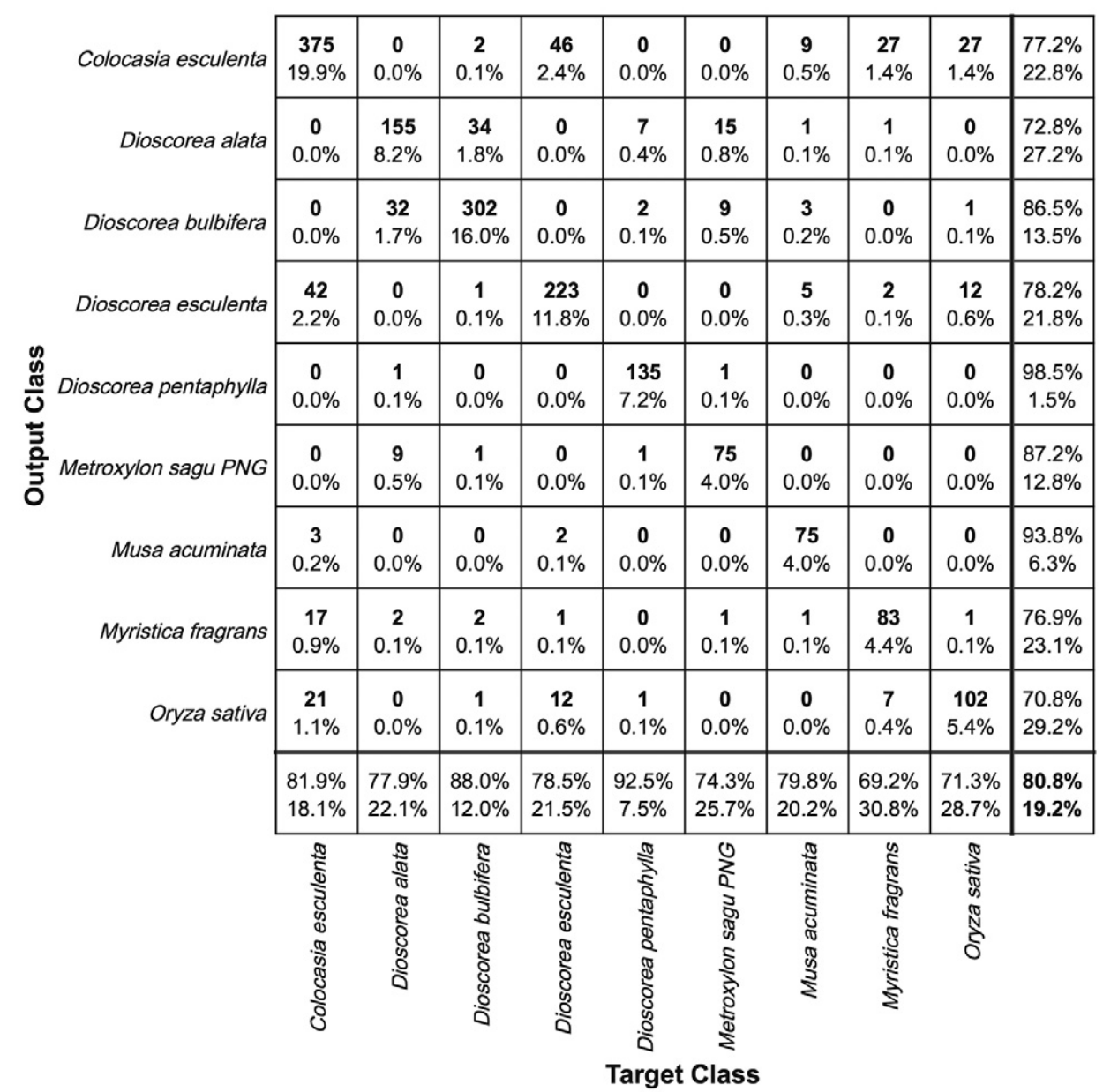

Fig. 14. Confusion matrix for the classifier: target class is the species from the reference set; output class is the species predicted by the classifier; number of grains classified for each target-output pair are reported (and as a percentage of total grains below each entry); accuracy (correct and incorrect) levels of each row and column are shown at the right and bottom.

Dioscorea spp. but exploitation of Dioscorea tubers has been argued for as early as ca. 40,000 B.P. in West Mouth of Niah Cave, Borneo (Barton and Paz 2007) and perhaps even earlier in the highlands of New Guinea (Summerhayes et al. 2010). Stone artifacts from early to mid-Holocene contexts at Kuk Swamp also yielded starch residues showing exploitation of possible Dioscorea spp., whether wild or cultivated (Fullagar et al. 2006; Haberle et al. 2017). These analyses have provided evidence for the antiquity of sago use in ISEA and significantly one of the first instances of the use of Myristica fragrans in the preparation of foodstuffs. 
Table 5. Prediction Scores and Strikes for Each of the Grains Attributed to Myristica FRAGRANS ${ }^{\mathrm{a}}$

\begin{tabular}{llcc}
\hline CODE & \multicolumn{1}{c}{ FILE NAME } & PREDiCTION SCORE & STRIKES \\
\hline 0306Asurf & 0306Asurf-0009 & 0.6 & 3 \\
0306Asurf & 0306Asurf-0010 & 0.6 & 3 \\
0306Asurf & 0306Asurf-0017 & 0.6 & 3 \\
3C6 & 3C6-0006 & 1 & 0 \\
Banda Island 3D08 Ceramic & 3D08-0004 & 1 & 0 \\
Banda Island 3D08 Ceramic & 3D08-0022 & 1 & 0 \\
Banda Island 3D08 Ceramic & 3D08-0024 & 0.8 & 1 \\
Banda Island 3I06 Ceramic & 3I06-0017 & 0.8 & 1 \\
Banda Island 3I08 Ceramic & 3I08-0012 & 0.8 & 1 \\
Banda Island 6C01 Ceramic & 6C01-0011 & 0.6 & 3 \\
\hline
\end{tabular}

${ }^{a}$ Grains with 0 strikes and a prediction score of 1 have the greatest confidence in identification to this plant taxa.

\section{DISCUSSION}

The results of archaeological research on Pulau Ay provide insights into early Neolithic lifeways in ISEA. When the first occupants of PA1 arrived about 3500 years ago, they likely encountered a densely forested island with a shoreline and reef structure roughly similar to the situation now (i.e., early twenty-first century C.E.). However, we currently lack proxy records from Pulau Ay that could illuminate these past ecological conditions. There is a probable mid-Holocene high sea level stand notch in the limestone cliffs on the coastline of Pulau Ay and many other islands in Maluku. For example, the photograph in Fig. 4 shows a bucket flotation crew working in the shade of a large limestone boulder; above their heads can be seen a probable mid-Holocene highstand notch approximately $1 \mathrm{~m}$ higher than modern high tide sea level. Such notches indicate a $1-1.5 \mathrm{~m}$ higher sea level around 6000-5000 B.P. (Woodroffe and Horton 2005), but this has not been confirmed with dating or precise measurements of height. The island is in a tectonically active area with the likelihood that significant local sea level changes due to tectonic uplift and subsidence have altered the reef structure many times in the past four millennia. The early Neolithic layers at PA1 (3500-3000 B.P.) show that the faunal aspect of subsistence focused primarily on marine sources. Pigs were present, but the very small number of pig remains in the lowest layers of the deposit are inconsistent with heavy reliance on domesticated stock. After $3000 \mathrm{~B}$. P., terrestrial fauna, pigs in particular, become more prevalent and marine fauna less so. This shift coincides with a change from thin, fine grain-tempered pottery to thicker, coarse grain tempered pots with shorter rims suggestive of a change in use from storage to cooking. In other cases where a relatively fine-grained chronology has been determined from ISEA Neolithic sites, similar shifts are evident (Amano et al. 2013; Denham 2013). Direct evidence for plant exploitation at PA1 includes starch grains recovered from residues on potsherds in the Neolithic layers L3-L6, including Dioscorea spp. (yams), Metroxylon sagu (sago), and Myristica fragans (nutmeg). Yams are commonly grown on Pulau Ay today. Sago does not currently grow on Pulau Ay or any of the Banda Islands (with the exception of one small tree growing at a spring on Banda Besar 
in 1997) as they lack the swampy conditions most suitable for sago survival. It is possible that before Dutch colonial period draining, the wet basin in the immediate vicinity of the PA1 site may have supported sago cultivation. Alternately, it may have been imported from southeast Seram, which has a long history of intensive sago cultivation and trade with Banda (Ellen 2003). This connection is also supported by the PA1 chert, which is possibly of Seram origin.

Nutmeg may have been used for its fruit (commonly eaten in dried form in Banda today), or as a spice or medicine extracted from the fruit, nutmeg kernel, or mace. Our results point to perhaps the earliest human use of this plant, which later became one of the most valuable globally-traded spices, and also help emphasize the point that humans consume plants for many reasons from basic nutrition to food flavoring to treatment of ailments. By the fourteenth century C.E. and possibly earlier, long distance traders were traveling to Banda to obtain nutmeg; this valuable spice brought the Banda Islands international renown during the early modern era (Lape 2000).

Pulau Ay is a small island lacking both terrestrial fauna and surface water. It likely would not have supported a permanent human population that did not have the technological advantages of domestic animals and water storage. However, evidence of pre-Neolithic occupation of the PA11 rockshelter suggests that the island was regularly visited by people targeting its rich marine reef resources (and possibly its other plant and animal resources) for several thousand years before more permanent populations were established in the early Neolithic. The most likely homeland for these visitors is the nearest large island of Seram, $100 \mathrm{~km}$ to the east. People who possessed sufficient knowledge of Pulau Ay and the seafaring skills to make regular return trips there would seem to be likely candidates for the first Neolithic settlers as well. With the exception of the new introduction of pottery, the pre-Neolithic rockshelter assemblages are very similar to the earliest Neolithic remains at PA1, including chert fragments and marine fish and shell. Later Neolithic assemblages from PA1 reflect a shift to a domestic animalbased diet, less reliant on local reef fish and shellfish. Pottery technology may also have changed to better utilize this change in subsistence. Sometime around 2300 B.P., the PA1 site was largely or totally abandoned; no other sites in the Banda Islands have so far been found that date to the period between 2300 and 1500 B.P. If this chronology holds up with further study, we must consider why these remote islands, which attracted the settlement of people who were quite connected to other places before and after this period (Peterson 2015), would have been abandoned for 800 years.

Studies of well-stratified open sites like PA1 can help illuminate the complex cultural processes at work during the Neolithic period, which saw the introduction of many new plants, animals, and technologies to ISEA. The results from PA1 demonstrate that these changes did not happen all at once, but rather were gradually adopted and adapted to allow people to utilize these tropical island seascapes in new ways.

\section{ACKNOWLEDGMENTS}

The 2007 fieldwork was conducted with the support of the National Geographic Society, with permission from Lembaga Ilmu Pengetahuan Indonesia (LIPI), as well as Maluku provincial and local governments, and was a collaborative effort between the Universitas Gadjah Mada, the University of Washington, and Balai Arkeologi Ambon. The 2009 fieldwork included the same partners and was conducted with support of the Henry Luce Foundation, with permission from Kementarian Riset dan Teknologi (RISTEK). Judith 
Field would like to thank the University of New South Wales and the University of Sydney for support and all of the authors wish to thank the participants in the fieldwork, as well as the residents and government officials of Pulau Ay and Banda Naira who graciously supported our project.

\section{REFERENCES CITED}

ADAms, Karen R.

1984 Evidence of wood-dwelling termites in archaeological sites in the Southwestern United States. Journal of Ethnobiology 4(1):29-43.

Amano, Noel, Philip Piper, Hsiao-chun Hung, and Peter Bellwood

2013 Introduced domestic animals in the Neolithic and Metal Age of the Philippines: Evidence from Nagsabaran, Northern Luzon. Journal of Island and Coastal Archaeology 8:317-335.

Anggraeni, Truman Simanjuntak, Peter Bellwood, and Philip Piper

2014 Neolithic foundations in the Karama valley, West Sulawesi, Indonesia. Antiquity 88:740.

Barton, Huw, and Victor Paz

2007 Subterranean diets in the tropical rain forests of Sarawak, Malaysia, in Rethinking Agriculture: Archaeological and Ethnoarchaeological Perspectives: 50-77, ed. T. Denham, J. Iriarte, and L. Vrydaghs. Walnut Creek, CA: Left Coast Press.

Bronk Ramsey, Christopher, and Sharen Lee

2013 Recent and planned developments of the program OxCal. Radiocarbon 55(2-3):720-730.

Bulbeck, F. David, AND NasRuddin

2002 Recent insights on the chronology and ceramics of the Kalumpang Site Complex, South Sulawesi, Indonesia. Bulletin of the Indo-Pacific Prehistory Association 22:83-99.

Castillo, Christina, and Dorian Q. Fuller

2010 Still too fragmentary and dependent upon chance? Advances in the study of early Southeast Asian archaeobotany, in 50 Years of Archaeology in Southeast Asia: Essays in Honour of Ian Glover: 93-111, ed. B. Bellina, E. A. Bacus, T. O. Pryce, and J. Wisseman Christie. Bangkok: River Books.

Cosgrove, Richard, Judith Field, and Asa Ferrier

2007 The archaeology of Australia's tropical rainforests. Palaeogeography, Palaeoclimatology, Palaeoecology 251:150-173.

Coster, Adelle C. F., And Judith H. Field

2015 What starch grain is that? A geometric morphometric approach to determining plant species origin. Journal of Archaeological Science 58:9-25.

Denham, Tim

2013 Early farming in Island Southeast Asia: An alternative hypothesis. Antiquity 87:250-257.

ELLEN, Roy F.

2003 On the Edge of the Banda Zone: Past and Present in the Social Organization of a Moluccan Trading Network. Honolulu: University of Hawai'i Press.

FIELD, JUdiTH

2008 Analysis of botanical remains: Starch grain analysis, MS 297, in Encyclopedia of Archaeology: 2078-2082, ed. D. Pearsall. Oxford: Elsevier.

Field, Judith, Lisa Kealhofer, Richard Cosgrove, and Adelle C. F. Coster

2016 Human-environment dynamics during the Holocene in the Australian Wet Tropics of NE Queensland: A starch and phytolith study. Journal of Anthropological Archaeology 44:216-234.

Fullagar, Richard, Judith Field, Tim Denham, and Carol Lentfer

2006 Early and mid Holocene tool-use and processing of taro (Colocasia esculenta), yam (Dioscorea sp.) and other plants at Kuk Swamp in the highlands of Papua New Guinea. Journal of Archaeological Science 33:595-614.

Haberle, Simon G., Carol Lentfer, and Tim Denham

2017 Palaeoecology, in Ten Thousand Years of Cultivation at Kuk Swamp in the Highlands of Papua New Guinea: 145-161, ed. J. Golson, T. Denham, P. Hughes, P. Swadling, and J. Muke. Terra Australis 46. Canberra, Australia: ANU Press. 
Jezek, P. A., And C. S. Hutchison

1978 Banda arc of eastern Indonesia: Petrology and geochemistry of the volcanic rocks. Bulletin Volcanologique 41(4):586-608.

LApe, Peter V.

2000 Contact and conflict in the Banda Islands, Eastern Indonesia 11th-17th centuries. Ph.D. diss. Brown University.

2002 Historic maps and archaeology as a means of understanding late precolonial settlement in the Banda Islands, Indonesia. Asian Perspectives 41(1):43-70.

2017 PA1 Archaeology Datasets. Open Science Framework (website), modified November 30. doi:10.17605/OSF.IO/ESJKF.

Lape, Peter V., Fadhila Arifin Aziz, Dian Ekowati, Jenn Huff, Wuri Handoko, Andre Huwae, Michael lahallo, Simon latupapua, Adhi Agus Oktaviana, Emily Peterson, Marlon Ririmasse, Karyamantha Surbakti, Joss Whittaker, and Lauryl Zenobi

2017 Reframing the Island Southeast Asian Neolithic: Local vs. regional adaptations, in Austronesian Diaspora: A New Perspective: 65-76, ed. B. Prasetyo, T. Surti Nastiti, and T. Simanjuntak. Yogyakarta: Gadjah Mada University Press.

Latinis, D. Kyle, and Ken Stark

2005 Cave use variability in central Maluku, Eastern Indonesia. Asian Perspectives 44(1):119-136.

O'CONNOR, SUE

2015 Rethinking the Neolithic in Island Southeast Asia, with particular reference to the Archaeology of Timor-Leste and Sulawesi. Archipel: Études interdisciplinaires sur le monde insulindien 90:15-47.

Oliveira, Nuno V.

2008 Subsistence archaeobotany: Food production and the agricultural transition in East Timor. Unpublished Ph.D. dissertation. Australian National University.

Peterson, Emily J.

2015 Insularity and adaptation: Investigating the role of exchange and inter-island interaction in the Banda Islands, Indonesia. Ph.D. diss. University of Washington.

Piperno, Dolores R., Ehud Weiss, Irene Holst, and Dani Nadel

2004 Processing of wild cereal grains in the Upper Paleolithic revealed by starch grain analysis. Nature 430:670-673.

Reepmeyer, Christian, Matthew Spriggs, Anggraeni, Peter lape, Leee Neri, Wilfredo P. Ronquillo, Truman Simanjuntak, Glenn Summerhayes, Daud Tanudirjo, and Archie Tiauzon

2011 Obsidian sources and distribution systems in Island Southeast Asia: New results and implications from geochemical research using LA-ICPMS. Journal of Archaeological Science 38:2995-3005.

Reimer, P. J., E. Bard, A. Bayliss, J. W. Beck, P. G. Blackwell, C. Bronk Ramsey, C. E. Buck, H. Cheng, R. Lawrence Edwards, M. Friedrich, P. M. Grootes, T. P. Guilderson, H. Haflidason I. Hajdas, C. Hatte, T. J. Heaton, D. L. Hoffmann, A. G. Hogg, K. A. Hughen, K. F. Kaiser, B. Kromer, S. W. Manning, M. Niu, R. W. Reimer, D. A. Richards, E. M. Scott, J. R. Southon, R. A. Staffm, C. S. M. Turney, and J. van der Plicht

2013 IntCal13 and Marine13 radiocarbon age calibration curves 0-50,000 years cal B.P. Radiocarbon 55:1869-1887.

SHIUng, Chung-CHING

2011 The implications of social, cultural, economic, and political interactions for ceramic evolution on the Banda Islands, Maluku Province, Indonesia. Ph.D. diss. University of Washington.

SiMANJUNTAK, TRUMAN

1995 Kalumpang: Hunian sungai bercorak Neolitic-Paleometalik di pedalaman Sulawesi Selatan. Aspek-aspek Arkeologi Indonesia 17. [Kalumpang: Patterns of Neolithic-Palaeometal riverine occupations in the South Sulawesi hinterland] Jakarta: Pusat Penelitian Arkeologi Indonesia.

Simanjuntak, Truman, And Hubert Forestier

2005 Research progress on the Neolithic in Indonesia, in Southeast Asian Archaeology: Wilhelm G. Solheim II Festschrift: 84-104, ed. V. Paz. Quezon City: University of the Philippines. 
LAPE ET AL. • NEW DATA FROM A NEOLITHIC SITE IN EASTERN INDONESIA 243

Spriggs, Matthew

2003 Chronology of the Neolithic transition in Island Southeast Asia and the Western Pacific: A view from 2003. Review of Archaeology 24:57-80.

2007 The Neolithic and Austronesian expansion within Island Southeast Asia and into the Pacific, in From Southeast Asia to the Pacific: Archaeological Perspectives on the Austronesian Expansion and the Lapita Cultural Complex: 104-125, ed. S. Chiu and C. Sand. Taipei: Center for Archaeological Studies, Academia Sinica.

Summerhayes, Glenn, Matthew Leavesley, H. Mandui, Andrew Fairbairn, Judith Field, Richard Fullagar, AND A. Ford

2010 Refocusing the boundaries: Human adaptation and use of plants in highland New Guinea from 49-44,000 years ago. Science 330:78-81.

Tite, M. S., V. Kilikoglou, and G. Vekinis

2001 Strength toughness and thermal shock resistance of ancient ceramics, and their influence on technological choice. Archaeometry 43(3):301-324.

Woodroffe, S. A., And B. P. Horton

2005 Holocene sea-level changes in the Indo-Pacific. Journal of Asian Earth Sciences 25(1):29-43. 